\title{
Assessment of HIV knowledge among university students using the HIV-KQ-18 scale: A cross-sectional study
}

\author{
Prashanth Talwar', Mohd Fadzil b Abd Rahman ${ }^{2}$ \\ ${ }^{1}$ Associate Professor, Faculty of Cognitive Sciences and Human Development; ${ }^{2}$ Deputy Vice Chancellor Student Affairs; \\ University Malaysia Sarawak, Sarawak, Malaysia
}

\section{Abstract}

Globally, the spread of HIV/AIDS has become a major health concern due to its pandemic proportions. Although people of any age are vulnerable to HIV, the younger populace are more at risk of becoming infected due to their lifestyle choices. The aim of the study was to assess the level of HIV-related knowledge among undergraduate university students using the HIV-KQ-18 scale, and thereby determine a relationship between the selected demographic variables and HIV knowledge. A cross-sectional study was conducted among 405 students enrolled in a Malaysian University, using a self-administered questionnaire. The HIV-KQ-18 scale was used to measure participants' basic knowledge about HIV, modes of its transmission and prevention. The study indicated that majority of the students (64\%) had adequate HIV-related knowledge. Accounting for socio-demographics, it was noted that lower age group, male and Faculty of Science students were the variables associated with higher HIV knowledge scores. Multiple regression analysis predicted three variables namely gender, faculty and relationship status as being significantly associated with knowledge. Essentially, findings from the study indicate significant differences in the gendered knowledge of HIV, demonstrating a need to conduct more gender-based studies in different settings. Furthermore, it is recommended that age and gender specific educational interventions strategies could be implemented to address misconceptions about HIV, modes of its transmission and effective prevention.

Keywords: HIV/AIDS, Knowledge, Undergraduate students, HIV-KQ-18 scale, Malaysia.

\section{Introduction}

World AIDS Day, which is held on December 1st each year is a reminder to people all over the world to not give up on issues surrounding human immunodeficiency virus (HIV) infection and acquired immunodeficiency syndrome (AIDS). HIV/AIDS is considered a major public health problem around the world with an estimated 35 million people living with this disease. ${ }^{1}$

For people living with HIV, the associated stigmatization and discrimination are major deterrents that discourages them from seeking timely testing and treatment. Many HIV/AIDS infected individuals are unable to work due to related opportunistic infections requiring expensive medications, thereby leading to adverse financial repercussions on their families. Moreover, the associated negative consequences indirectly affect communities, nations and the whole world. Hence, it is imperative to promote awareness about HIV/AIDS among all populations in order to diminish risk, infection and mortality among them.

Although people of any age are vulnerable to HIV, the younger populace are more at risk of becoming infected. Young adults, particularly college and university students who are in their late teens and early twenties, are in a phase of development when interpersonal relationships are formed and sexual experimentation takes place, making them particularly vulnerable to HIV infection and

\section{Practice Points}

- In the absence of cure, HIV infection remains prevalent all over the world, especially among young people.

- Evaluation of HIV-related knowledge level among students were necessary to determine any relevant socio-demographic factors related to that knowledge.

- Majority of the students demonstrated good knowledge of HIV infection, however gender differences were observed.

- Three variables namely gender, faculty and relationship status were found to be significantly associated with knowledge.

- A well designed sex education program should be introduced at high school level to prevent HIV prevention and transmission.

sexually transmitted diseases (STDs). Many factors increase their susceptibility. These factors include a lack of knowledge about HIV/AIDS, lack of education and life skills, poor access to health services and commodities, early sexual debut, early marriage, sexual coercion. ${ }^{2}$ In order to prevent becoming infected with HIV, young people need the requisite information

Correspondence: Dr. Prashanth Talwar, Associate Professor, Faculty of Cognitive Sciences and Human Development; University Malaysia Sarawak, 94300 Kota Samarahan, Sarawak, Malaysia. Email: typrashanth@ppp.unimas.my. 
about HIV and its associated risk factors. While abstinence from premarital sex may be considered the best way to protect against STDs and HIV, having adequate comprehensive knowledge about the diseases provides the key to its prevention. Therefore, awareness of both scientific and social aspects of HIV infection plays an important role in fostering positive attitudes among young people, and may deter them from indulging in risky sexual behavior and drug use.

Globally, people between the ages 15 to 24 years represent $45 \%$ of all people living with HIV. Young people in this age group make up nearly half of all new infections every year. ${ }^{1}$ As in most parts of the world, it is alarming to note that the HIV infection rate and AIDS cases in Malaysia are also showing a rapid increase among young people. ${ }^{3}$ The Ministry of Health statistics show that $31 \%$ of new HIV infections were found in young adults aged 20 to 29 years, indicating that majority of newly reported cases belonged to individuals in their twenties.

Malaysia is currently classified as having a concentrated HIV epidemic with more than one third of total 87,710 reported infections registered in the country to be those detected in younger people between the ages of 13 to 29 years. ${ }^{4}$ Gaining insight into the perceptions and factors influencing the behavior of teens is critical in HIV and AIDS prevention. ${ }^{5}$

In a study conducted by $\mathrm{Ng} \& \mathrm{Kamal}^{6}$ on male and female private college students aged between 18 and 22 years old in Malaysia, it was reported that most participants were concerned about pregnancy rather than sexually transmitted diseases or HIV infection, when they interpreted safe sex. Reasons for not practicing safe sex include trust between sex partners, complacency, low perception of risk, and negative attitudes towards condom use.

In the context of the evaluation of prevention programs, it is necessary to have valid, reliable and parsimonious instruments to assess the degree of knowledge in the target population. Few questionnaires are specifically designed for adolescents. ${ }^{7}$ The brief HIV Knowledge Questionnaire (HIV-KQ-18) developed by Carey \& Schroder ${ }^{8}$ consists of 18 items and was designed to provide a more concise and well-established measure of HIV-related knowledge. This instrument is particularly useful in settings where self-reported knowledge of HIV is needed and is thereby suitable for use in an educational institution.

The main aim of the study was to assess the level of HIV-related knowledge among university students, using the HIV-KQ-18 scale. This study also aims at finding the relationship between select demographic variables and HIV knowledge.

\section{Materials and Methods}

\section{Participants}

The participants for this cross-sectional study comprised of 405 undergraduate students ( $42 \%$ males and $58 \%$ females) from a Malaysian University. Ages of the participants were between 19 to 24 years. $(\bar{x}=21$, $\mathrm{SD}=1.04)$.

\section{Tool}

Data was collated using the well validated HIV-KQ-18 scale. This brief self-administered questionnaire was used as an instrument to measure and assess HIVrelated knowledge of the participating students. The first section of the English language questionnaire was used to garner data on the socio-demographic backgrounds of the participants. The ensuing knowledge section, based on the HIV-KQ-18 scale, consisted of questions related to HIV, modes of its transmission and prevention.

For each of the 18 true/false, HIV-related questions, a score of 1 was assigned to each 'correct' answer. 'Don't know' and 'non-responses' were coded as 'incorrect' and assigned a score of 0 . No deductions were made for any answer. Assessments were based on the analysis of the summation of these scores, which had a possible range of 0 to 18 , whereby higher scores indicated greater knowledge of HIV. This scale was found to be reliable, and Cronbach's alpha coefficients of 0.75 to 0.89 have been reported. ${ }^{8}$

\section{Procedure}

Undergraduate students enrolled in different academic programs in the participating university were assessed for knowledge of HIV infection and associated risk factors. A purposive sampling technique was adopted for selecting the sample. Thereby, the questionnaires were administered to students belonging to the Faculty of Arts and Faculty of Science. The survey was conducted during the last 15 minutes of a 2-hour class lecture. Participation was voluntary and students who declined to participate were excluded from the study.

Prior to the survey, students were informed about the purpose of the research and assured about the confidentiality of their feedback. After obtaining written consent, participants were encouraged to fill in the questionnaire without consulting each other. Upon completion, the responses were retrieved immediately from the participants. This self-funded study received approval from the University Research Committee.

\section{Statistical analysis}

Statistical analyses were conducted with SPSS version 20. The data was normally distributed. Median split was used to denote students knowledge on the HIV-KQ -18 scale. Median split was considered a better representation of low versus high values for the present study. Independent t-test was used to find difference between means. Multiple linear regression analysis was used to develop a model for predicting HIV knowledge among university students. Logistic regression was used to predict the odds of an event for selected variables. The level of significance was set at $p<0.05$.

\section{Results}

Demography

Of the 405 study participants, $42 \%$ were males and $58 \%$ 
were females. The mean age was 21 years $(\mathrm{SD}=1.04)$. Student participants between 19 and 20 years were considered as lower age group and comprised $17 \%$ of sample, whereas $83 \%$ were between 21 and 24 years and considered as higher age group. The religious profiles of the sample were, 61\% Muslims, 33\% Christians, 5\% Buddhists and 1\% Hindus. The monthly income of parents ranged from RM300 to RM9000. High income families were categorized as those earning more than RM 3000 per month and comprised $25 \%$ of sample, low income families were categorized as those earning less than RM3000 per month and comprised $75 \%$ of sample. The majority of students were enrolled in the Faculty of Science (64\%) and the remaining were from the Faculty of Arts (36\%). None of the students were married.

\section{$H I V-K Q-18$ score}

The highest score obtained in this section was 14 out of 18 whilst the lowest was 2 out of 18 . Median score on the HIV-KQ-18 scale was 7. Dichotomous scoring of the responses were stratified into high (scores $\geq 7$ ) and low (scores $<7$ ). Majority of the participants $(64 \%)$ scored relatively high on HIV knowledge $(\overline{\mathrm{x}}=8.73$, $\mathrm{SD}=1.62)$ and the remaining $36 \%$ scored low $(\overline{\mathrm{x}}=5.05$, $\mathrm{SD}=0.99$ ). The independent t-test revealed significant difference in the mean between the two scores $(\mathrm{t}=24.66$, $p<0.05)$.

\section{Age group and knowledge}

Students in the lower age group had a better knowledge $(\overline{\mathrm{x}}=0.78, \mathrm{SD}=0.41)$ compared to those in the higher age group $(\overline{\mathrm{x}}=0.61, \quad \mathrm{SD}=0.48)$. The independent $\mathrm{t}$-test revealed significant difference in the mean scores between lower age group and higher age group $(t=3.04$, $\mathrm{p}<0.05)$.

\section{Gender and Knowledge}

he mean HIV-KQ-18 score among the male group was higher $(\overline{\mathrm{x}}=0.72, \mathrm{SD}=0.45)$ while the female group mean score was lower $(\bar{x}=0.58, \mathrm{SD}=0.9)$. The independent $\mathrm{t}$ test revealed significant difference in the mean scores of male and female students $(\mathrm{t}=2.82, p=<0.05)$.

\section{Awareness of HIV knowledge among genders}

Male and female students differed in their knowledge on HIV. Male students had significantly $(p<0.05)$ better knowledge about certain items in the HIV-KQ-18 scale when compared to female students. For example:
- Pulling out the penis before a man climaxes/cums keeps a woman from getting HIV during sex (Male $\overline{\mathrm{x}}=0.36, \mathrm{SD}=0 . \quad 48 ;$ Female $\overline{\mathrm{x}}=0.26$, $\mathrm{SD}=0.44)$.

- A woman can get HIV if she has anal sex with a man (Male $\bar{x}=0.83, \mathrm{SD}=0.37$; Female $\overline{\mathrm{x}}=0.76$, $\mathrm{SD}=0.42)$.

- There is a female condom that can help decrease a woman's chance of getting HIV (Male $\overline{\mathrm{x}}=0.72$, $\mathrm{SD}=0.45$; Female $\overline{\mathrm{x}}=0.54, \mathrm{SD}=0.50$ ).

- Having sex with more than one partner can increase a person's chance of being infected with HIV (Male $\bar{x}=0.97, \mathrm{SD}=0.17$; Female $\overline{\mathrm{x}}=0.93$, $\mathrm{SD}=0.25)$.

- Taking a test for HIV one week after having sex will tell a person if she or he has HIV (Male $\overline{\mathrm{x}}=0.53, \mathrm{SD}=0.50 ;$ Female $\overline{\mathrm{x}}=0.37, \mathrm{SD}=0.48$ ).

\section{Socio economic status and knowledge}

Students who were from higher income families (>RM 3000 per month) had a better knowledge $(\overline{\mathrm{x}}=7.50, \quad \mathrm{SD}=2.23)$ compared to lower income families ( $<\mathrm{RM} 3000$ per month), $(\overline{\mathrm{x}}=7.38, \mathrm{SD}=2.30)$. However, $\mathrm{t}$-test was not significant $(\mathrm{t}=0.49, p>0.05)$.

\section{Faculty and knowledge}

Students from the Faculty of Science had better knowledge $(\bar{x}=7.12, S D=2.48)$ compared to students from the Faculty of Arts $(\bar{x}=7.60, S D=2.31)$. The independent t-test revealed significant difference in the mean scores between faculties $(\mathrm{t}=2.40, p<0.05)$.

\section{Sexual behavior and knowledge}

It was found that students who indulged in sexual behavior had better knowledge $(\overline{\mathrm{x}}=8.05, \mathrm{SD}=2.14)$ compared to those who did not indulge in sexual behavior $(\overline{\mathrm{x}}=7.35, \mathrm{SD}=2.27)$. The independent t-test revealed significant difference in the mean scores $(\mathrm{t}=2.01, p<0.05)$.

\section{Relationship status and knowledge}

Eighteen percent of male students and 29\% female students were in a relationship. Ten percent of students who reported being in a relationship also stated to have indulged in sexual behavior with their partner. A multiple regression was calculated to predict HIV knowledge based on gender, faculty, relationship status, income, age, religion and sexual behavior using the enter method.

Table 1: Regression analysis and HIV knowledge level

\begin{tabular}{|l|c|c|c|c|}
\hline \multirow{2}{*}{ Variables } & \multicolumn{2}{c|}{ Unstandardized Coefficients } & \multicolumn{2}{c|}{ Standardized Coefficients } \\
\cline { 2 - 4 } & B & Std. Error & Beta & $p$-value \\
\hline Gender & 0.64 & 0.23 & 0.14 & $0.006^{*}$ \\
\hline Faculty & 0.50 & 0.26 & 0.11 & $0.04^{*}$ \\
\hline Relationship & 0.51 & 0.23 & 0.12 & $0.03^{*}$ \\
\hline Income & 0.00 & 0.00 & 0.10 & 0.56 \\
\hline Age & 0.15 & 0.12 & 0.07 & 0.15 \\
\hline Religion & 0.01 & 0.19 & 0.02 & 0.61 \\
\hline Sexual behavior & 0.25 & 0.40 & 0.04 & 0.51 \\
\hline
\end{tabular}

$* p<0.05$ 
Table 1 gives information for the predictor variable entered into the model. Income, age, religion and sexual behavior were not a significant predictor, but the other three variables were. The overall model fit was $6 \%$. A significant linear regression was found ( $F(2,397)$ $=3.64, \mathrm{p}<.001)$.

\section{Discussion}

HIV/AIDS knowledge is an important component of HIV/AIDS risk prevention strategies that may influence engagement in high risk behavior. ${ }^{9}$ In the present study, it was observed that a significant proportion of the students (64\%) had adequate HIV-related knowledge, however a moderately small proportion (36\%) had lower HIV KQ-18 scores suggesting inadequate knowledge. This finding is consistent with a study conducted by Jahanfar ${ }^{10}$, who reported that knowledge of HIV among university students in Malaysia was high but there were still some remaining misconceptions. However, it is debatable whether improved HIV knowledge could lead to reduced risky sexual behavior and enhanced positive outcomes. It is evident from the reported findings by Tee \& Huanh ${ }^{11}$ who assessed that the level of knowledge about reproductive and sexual rights was quite low among Malaysian students and thereby recommended the Ministry of Education to incorporate reproductive knowledge and sexual rights based curricula in high schools and institutions of higher learning.

Although various measures have been implemented to increase awareness, gaps of HIV knowledge remain prevalent in various populations. According to the UNDP Country Report on Malaysia, ${ }^{12}$ all members of the community who participated in a survey had heard of HIV/AIDS, but there were differences in knowledge levels. The terms 'HIV' and 'AIDS' were known to them, but the people remained unaware of the details of transmission of the disease indicating that twenty years into the epidemic and yet knowledge of the community was shallow. In light of this background, a conclusion could be drawn that although young people in Malaysia had adequate HIV-related knowledge, they still retained many misconceptions thereby preventing them from making informed choices and taking appropriate action.

The findings of this study also indicated an association between some socio-demographic variables and students level of HIV-related knowledge. The analysis of data revealed that students in the lower age group (19 to 20 years) had a better knowledge compared to older age group (21 to 24 years). However, in a similar study conducted on secondary schools and colleges by Maswanya, ${ }^{13}$ it was found that teenage students scored significantly lower than older students, on both transmission and prevention. This was also indicated by other studies, which stated that higher levels of knowledge were associated with older students, which was not observed in the present study. This inconsistency might be attributed to the fact that younger students in the present study could have been exposed to HIV risk prevention programs, thereby giving them an opportunity to have more health care information.

The results of the present study also indicated a reasonably high level of HIV-related knowledge among male students when compared to their counterparts. This is comparable to the results of a study conducted by Milani \& Azarghashb ${ }^{14}$ who concluded that majority of female students had weak knowledge, whereby their attitudes and practice could lead them to unhealthy conditions. The authors also opined that although male students were sexually more active, they were able to prevent themselves from getting infected with STDs, since they were better informed than the female students. However, in another study done in Malaysia by Low $^{15}$ it was reported that information on reproductive and sexual health may not be accurate, and this may affect their decision-making and subsequently affect their behavioral practices.

Negative attitudes toward controversial aspects of human sexuality and lower sex knowledge scores among students can be predicted on the basis of background and socio-demographic variables. ${ }^{16}$ Students who came from higher income families (>RM3000 per month) had a better knowledge compared to lower income families $(<\mathrm{RM} 3000$ per month). However, t-test is not significant; hence knowledge could not be associated to the economic background of students.

The HIV virus, like any other, has no boundaries and does not distinguish between class or religion. ${ }^{17}$ The mean knowledge score for Chinese students was higher $(\overline{\mathrm{x}}=7.68, \mathrm{SD}=2.08)$ compared to students of other races $(\overline{\mathrm{x}}=7.18, \mathrm{SD}=2.04)$. Similar findings were observed by Siti et al. ${ }^{18}$ who reported that Chinese adolescents had significantly higher mean sexual knowledge scores than Malay and Indian adolescents. The interactions between religious affiliation, education, HIV knowledge, and HIV-related sexual behaviors among youth are poorly understood. ${ }^{19}$ In the present study, it was noted that religion was not significantly associated to the level of HIV knowledge.

As anticipated, when comparing faculties, there were statistically significant differences in HIV knowledge between students enrolled in the Faulty of Science and those from the Faculty of Arts, with former scoring more than the latter. This is comparable to the findings by Rai et al. ${ }^{20}$ who reported that the science students had better awareness on STD compared to the arts students. It appears that having scientific knowledge related to HIV may correlate to a better understanding of the disease.

Not surprisingly, the present study also revealed that only a small percentage of students $(10 \%)$ indulged in sexual behavior. This is consistent with a previous study conducted in Malaysia, which reported that prevalence of pre-marital sex among students was still low compared to the neighboring countries and developed countries. $^{21}$ Students who were sexually active had 
better HIV knowledge compared to those who were sexually inactive. Multiple regressions were performed to determine factors that predict HIV knowledge level. The regression analysis predicted three variables namely gender, faculty and relationship status. It was earlier reported in this study that male students had better knowledge compared to female students. The odd of male students having better knowledge is 1.7 times greater as opposed to female students $(95 \%, \mathrm{CI}$ 1.14-2.75). This clearly indicates that female students with inadequate knowledge are at risk. In the realm of HIV knowledge, science students have the advantage of learning about the diseases and modes of its transmission, as a part of their faculty curriculum. The personal involvement of being in a relationship may influence students to be more aware of conception and STDs. The value of coefficient reveals that the presence of having a relationship increases the chance of sexual behavior and is 9 times higher than not having a romantic relationship (95\%, CI 3.59-24.48).

The relationship between knowledge about HIV/AIDS and its associated risky behavior is complex and has not been sufficiently explored. ${ }^{22}$ In their study, Okonta et $a l .{ }^{23}$ concluded that knowledge of HIV/AIDS among school adolescents in Nigeria has not significantly influenced their sexual behavior. Similar findings were observed by Marisen ${ }^{24}$ who confirms that the perception of being at risk of contracting HIV/AIDS and knowledge of transmission dynamics has not necessarily translated into change in behavior relative to the pandemic. One point that may drive this inference process is the degree to which the content of knowledge on which the attitude is based is directly relevant to the goal of the behavior. ${ }^{20}$ The question whether having improved knowledge about HIV/AIDS will deter people from taking risky behavior may be debated. Festingers ${ }^{25}$ theory of cognitive dissonance postulates that there is an inconsistency between people's attitude, beliefs and their actual behavior. Disparities between beliefs and perceived behavior are discomforting and hence people strive to reduce dissonance. People feel more comfortable when they agree with issues they like and disagree with issues they dislike. Notwithstanding these conclusions, it is crucial that for the implementation and success of prevention strategies, we understand how knowledge can impact on students behavior and beliefs with regard to HIV.

The present study has some limitations that should be considered when interpreting the results. Firstly, since the study was cross-sectional in nature, casualty could not be analyzed. Secondly, a self-reported questionnaire generally has potential for recall bias. Moreover, due to the sensitive nature of the subject, some students may have under reported, in order to give socially acceptable responses. Thirdly, the HIVKQ-18 is a shorter version of the HIV-KQ-45, hence assessment of the comprehensive knowledge of HIV amongst students could not be conducted. However, for the purpose of this study, the HIV-KQ-18 was chosen for its briefness and viability, which helped the students to complete the scale in time. Lastly, this study makes use of non-probability sampling with a small sample size and was restricted to only one university, hence the results cannot be generalized to the Malaysian student population as a whole.

\section{Conclusion and recommendations}

The current study sought to evaluate the level of HIV knowledge, modes of its transmission and prevention, among the students from a Malaysian University. The baseline findings revealed that most students demonstrated a good knowledge about HIV infection. The findings also indicated clear relationships between a set of socio-demographic variables and knowledge. Greater HIV-related knowledge was associated with younger age, male and having scientific academic background. The research posits that inadequate knowledge on the mode of HIV transmission and prevention may increase the likelihood of unsafe sexual practices thereby increasing risk of infection. Because age and gender differences were identified, it is important that this problem can be addressed by establishing well-structured age and gender specific health promotion programs in educational institutions to address misconceptions about transmission of HIV and its prevention. Universities should have more health counselors who can provide health education as well as counseling services to students. In spite of concerns regarding the implementation of sex education programs in institutions of learning, it is the authors opinion that sex education does not encourage sexual experimentation. On the contrary it may help provide accurate information to students to make informed decisions, thereby preventing STDs and unwanted pregnancy. This study provides preliminary evidence for future research to investigate and evaluate whether acquisition of HIV-related knowledge would deter students from high risk behavior.

\section{Competing interest}

The authors declare that they have no competing interests.

\section{References}

1. UNAIDS. Results: UNAIDS World AIDS Day Report 2012. Geneva: UNAIDS, 2012.

2. Rahnman R, Rampal L, Lye MS, Rahman HA. Factors Influencing Students' Attitude Towards HIV/AIDS in a Public University, Malaysia. Glob J Health Sci 2011; 3(1):128-34.

3. Wong LP, Chin CKL, Low WY, Jaafar N. HIV/ AIDS-Related Knowledge among Malaysian Young Adults: Findings from a Nationwide Survey. J Int AIDS Society 2008; 10:148.

4. Ministry of Health Malaysia (MOH). National Service Survey in UNGASS Country Progress Report Malaysia. Kuala Lumpur: MOH, 2010.

5. Facente AC. Adolescents and HIV: knowledge, behaviors, influences, and risk perceptions. $J$ 
Sch Nurs 2001;17(4):198-203.

6. Ng C-J, Kamal SF. Bridging the gap between adolescent sexuality and HIV risk: The urban Malaysian perspective. Singapore Med J 2006; 47(6):482-490.

7. Espada JP, Huedo-Medina TB, Orgilés M, Secades R, Ballester R, \& Remor E. Psychometric properties of the HIV/AIDS Knowledge Scale for Spanish adolescents (HIV -KS). Health Addict 2009; 9(2):149-64.

8. Carry MP, Schroder KEE. Development and Psychometric Evaluation of the Brief HIV Knowledge Questionnaire. AIDS Edu Prev 2002;14:174-84.

9. Anderson KG, Beutel MA. HIV/AIDS Prevention Knowledge among Youth in Cape Town, South Africa. J Soc Sci 2007;3(3):14351.

10. Jahanfar S, Lim AW, Loh MA. Improvements of knowledge and perception towards HIV/ AIDs among secondary school students after two hours talk. Med J Malaysia 2008;63(4): 288-92.

11. Tee Y, Huang M. Knowledge of HIV/AIDS and attitude towards people living with HIV among the general staff of a public university in Malaysia. $J$ Soc Aspects HIV/AIDS Res Alliance 2009;6(4):179-87.

12. Zulkifli SN, Lee MHS, Low WY, Wong YL. Study on the impact of HIV on People Living with HIV, their families and community in Malaysia. Kuala Lumpur: United Nations, 2007.

13. Maswanya ES, Moji K, Horiguchi I, Nagata K, Aoyagi K, Honda S, Takemoto T. Knowledge, risk perception of AIDS and reported sexual behaviour among students in secondary schools and colleges in Tanzania. Health Edu Res 1999;14(2): 185-96.

14. Milani HS, Azarghashb E. Knowledge and attitudes of female students who live in Tehran dormitories, towards STDs and sexual relationship. Iranian J Clin Infect Dis 2011;6 (1):35-40.
15. Low WY. Impact of Sexual Health Course on Malaysian University Students. Med J Malaysia 2004;59(4):443-9.

16. McKelvey RS, Webb JA, Baldassar LV, Robinson SM, Riley G. Sex knowledge and sexual attitudes among medical and nursing students. Aust N Z J Psyh 1999; 33(2):260-6.

17. Azmi S 2006. The role of Religious leaders in the fight against HIV/AIDS. Based on a UNDP supported project "Islam and HIV/AIDS", Page 10.

18. Siti Nor Y, Wong Fui-Ping, Rozumah B, Maroamo M, Rumaya J, Mansor AT. Factors related to sexual knowledge among Malaysian adolescents. Jurnal Kemanusiaan 2010;16:2132.

19. Tung W, Ding K, Farmer S. Knowledge, attitudes, and behaviors related to HIV and AIDS among college students in Taiwan. $J$ Assoc of Nurs AIDS Care 2008;19 (5):397-408.

20. Rai Y, Singh J, Dutta T, Tripati JS. Awareness about prevention and transmission of HIV/ AIDS among people getting higher education. Indian J Prev Soc Med 2009; 40(1):43-9.

21. Manafa MRA, Tahira MM, Sidib H, Jaafarb NRN, Dasc S , Malekd AMA. Premarital sex and its predicting factors among Malaysian youths. Compr Psychiatry 2014 Jan;55 Suppl $1: \mathrm{S} 82-8$

22. Tameru B, Gerbi G, Nganwa D, Bogale A, Robnett V. The Association between Interrelationships and Linkages of Knowledge about HIV/AIDS and its Related Risky Behaviors in People Living with HIV/AIDS. J AIDS Clinic Res. 2012:;3(7):1-7..

23. Okonta PI, Oseji MI. Relationship between knowledge of HIV/AIDS and sexual behaviour among in-school adolescents in Delta State, Nigeria. Niger J Clin Pract 2006;9(1):37-9.

24. Marisen M. Behavioural Change vis-à-vis HIV/ AIDS knowledge mismatch among adolescents: The case of some selected schools in Zomba. Nordic J African Stud 2008; 17(4):288-99.

25. Festinger L. A theory of cognitive dissonance. Evaston IL: Row, Peterson and Company, 1957. 